\title{
The Theory of Catastrophe Risk Financing: A Look at the Instruments that Might Transform the Insurance Industry"
}

\author{
Stanley Mutenga ${ }^{\mathrm{a}}$ and Sotiris K. Staikouras ${ }^{\mathrm{b}}$ \\ ${ }^{a}$ Salford Business School, The University of Salford, Maxwell Building, Manchester M5 4WT, U.K. \\ E-mail: s.mutenga@salford.ac.uk \\ ${ }^{\mathrm{b}}$ Risk Institute and Emerging Markets Group, Cass Business School, City University, 106 Bunhill Row, \\ London EC1Y 8TZ, U.K. \\ E-mail: sks@city.ac.uk
}

The current study reviews the risk financing techniques employed in the insurance markets and looks at the changing field of the risk management arena. The overarching view is that apart from the traditional channels of financing risk, alternative routes should be explored. The latter is strengthened with the surfacing of off-balance sheet instruments in modern financial markets. The paper extends the discussion to the layered risk financing approach and reinforces its importance. That is, cash flow engineering instruments are employed to match different segments of the loss distributions. The role of insurance risk capital to assume extreme losses is further discussed, while reinsurance still remains a form of capital restructuring. Taken all together, the intention is that risk financing should be able to release assets committed to liabilities, and should reduce the cost of risk capital in sponsoring all-purpose equity. Finally, risk management platforms are redefined, while the securitisation of insurance risk is explored along with its effectiveness and possible caveats. The Geneva Papers (2007) 32, 222-245. doi:10.1057/palgrave.gpp.2510127

Keywords: (re)insurance business; alternative risk transfer; catastrophe risk; hedging vehicles; risk financing; insurance securitisation

JEL classification: G10; G20; G22

\section{Introduction}

Loss prevention and optimal insurance policies have long been an important part of the insurer's mission to provide effective protection against various types of risk. ${ }^{1}$ Modern insurance theory has largely concentrated on the problem of how a large number of risk-averse agents can beneficially exchange their risks at a single point in time. Over a long enough horizon, the probability that a risk will take place translates into near certainty and, thus, the question becomes not "if" but "when". Uncertainty

\footnotetext{
* The authors are grateful to Paul Dawson and Kevin Dowd for their support. The paper has greatly benefited from the referees' thorough reviews and we are indebted to them. Research support by Argyro Banila and Aspasia Louvari, at the early stages of this study, is greatly appreciated. The usual disclaimer applies.

${ }^{1}$ Arrow (1963), Raviv (1979); see Gollier (1992) for a survey.
} 
arises from our inability to predict future outcomes. The level of uncertainty is important, since it affects and complicates the decision-making process. "More possibilities than outcomes" is probably the simplest and most intuitive approach to uncertainty. One of the certain characteristics of insurance companies is the pooling of risks and risk transfer. The former involves the grouping of various exposures, so that the law of large numbers can operate to provide an accurate prediction of future losses. From an insurer's point of view, if losses are predictable, objective risk is reduced. Risk transfer is the other important element, where risk is shifted from the insurer to the reinsurer or to any other third party that is willing to assume such $\operatorname{risk}(\mathrm{s})$.

The globalisation of financial markets and the rapid evolution of technology have completely changed the nature and impact of various risks, over the last two decades. These changes had also a spillover effect on the contracts' structure, organisational form and corporate restructuring of insurance firms. ${ }^{2}$ Modern financial institutions, mainly banks and insurers, face various challenges ranging from the nature of their activities to their solvency management. An area in which risk management innovation has been particularly interesting is the hedging and securitisation of catastrophe risk. It was in the U.S., during the 1990s, that catastrophe insurance caught the attention of global financial markets, and recently extended into the developing countries. ${ }^{3}$ The novelty of risk hedging and securitisation in the insurance industry ${ }^{4}$ was first speculated some 25 years ago, ${ }^{5}$ well before it became tangible in the Chicago Board of Trade (CBOT) in 1992. Interestingly, the idea was launched even before the word "securitisation" was first coined by academics and market practitioners.

Catastrophe insurance covers certain major disasters that cause widespread damage, like floods, hurricanes, tropical storms, earthquakes, wildfires, volcanic eruptions, etc. Many (re)insurers could become insolvent or seriously impaired and, therefore, unable to continue insuring the same volume of business. ${ }^{6}$ Such events, and possibly others, ${ }^{7}$ may be covered by a comprehensive catastrophe insurance policy. Many insurance companies, however, require separate policies for each type of event, while some will not even insure specific types of episodes in certain areas. Sometimes catastrophe insurance policies will only begin payment if an event has been declared as a disaster by the government. The price of catastrophe insurance will vary depending on the types of catastrophic events to be insured against, the location of the property, the amount of coverage desired, and perhaps whether or not the property has certain features that would make it more likely to be damaged or destroyed during

\footnotetext{
${ }^{2}$ Doherty and Dionne (1993), Staikouras (2006).

${ }^{3}$ Freeman (2001), Durbin (2001a, b).

${ }^{4}$ Cummins et al. (1997), Doherty and Schlesinger (2002).

${ }^{5}$ Goshay and Sandor (1973).

${ }^{6}$ Such serious situation(s) could emerge if either simultaneously or sequentially a number of big catastrophes take place at a certain point in time.

${ }^{7}$ Nowadays ordinary people, corporate businesses and insurers face not only natural disasters, but also man-made catastrophes such as terrorism activities; see Swiss Re (2002), Achleitner et al. (2002), Jaffee and Russell (2002), Doherty et al. (2003), and Mutenga and Staikouras (2007).
} 
a catastrophe. Verrall ${ }^{8}$ adeptly portrays the risk(s) of climate change and warns that disasters like hurricane Katrina could raise premiums dramatically and render some of the world uninsurable. The recognition of such exposure(s) has stimulated the industry efforts to address the problem of catastrophes. Insurance regulators, legislators, government agencies, investment bankers, and academics have all contributed to the public policy debate on this critical issue.

The main objective of the current work is to survey the issues related to alternative risk transfer within the insurance industry. Financing and capital budgeting decisions are discussed along with the importance of core capital in the insurance business. The latter is extended to incorporate the notion of risk capital ${ }^{9}$ as well as the "optimisation" of the cost of capital equation. From a viewpoint of the modern insurance theory and practice, the paper analyses issues surrounding catastrophe insurance and recites the pertinent risk management techniques. The effectiveness of those tools is presented and possible caveats are further discussed. The study also delves into how various risk financing and risk transfer instruments help insurance companies restructure their balance sheets. The latter is a decisive factor in order to achieve "optimal" capital structures, while maintaining an acceptable level of firmwide risk.

In what follows, the next section presents a brief overview of the insurance firm's funding options. The following section introduces the market for financing risk and presents a layered risk financing structure. The conventional approaches to cover insurance losses are hosted in the next section, while the penultimate section broadens the survey by incorporating risk management platforms available in modern capital markets. Finally, the last section provides an overall discussion along with some concluding remarks.

\section{The funding puzzle and risk capital}

Insurance companies like any other corporation require funding, with the primary sources of financing being equity and premiums on policies issued. These two sources of funding form the primary claims on the assets of an insurance firm. The interesting puzzle surfaces when firms start deciding their sources of financing and even try to optimize them not only in the insurance business, but in any other industry. Priority rules that apply to other corporations, in times of financial distress, apply equally to insurers. In the U.K., the Financial Services Authority enforces such principle, on behalf of the policyholders, so as to preserve value for policyholders in cases of financial distress or bankruptcy. Regulators require companies to hold a certain amount of capital, ${ }^{10}$ in excess of the value of estimated liabilities, as a cushion to

\footnotetext{
${ }^{8}$ Verrall (2006).

${ }^{9}$ Risk capital is defined as the capital available to cover extreme losses. We categorise that as part of the firm's shareholders funds. Merton and Perold (1993) define risk capital as the amount required to assure payments of an asset or liability.

${ }^{10}$ For an excellent discussion on the capital requirements and the risks of financial intermediaries, the interested reader is referred to Saunders and Cornett (2006).
} 
policyholders, which at the same time aims to reduce the risk of bankruptcy. Insurance companies like banks are highly leveraged, which means their net worth (cushion) is quite sensitive to any risk factor(s) that affect asset and liability values.

The main purpose for insurers, when choosing a form of risk funding, is to minimize unfunded risk known as the policyholder surplus deficit. ${ }^{11}$ Value accruing to policyholders is preserved whenever the cushion is wider relative to its liabilities. The higher the cushion set for the risk score ${ }^{12}$ measuring the probability of survival, the more protected the policyholders will be and the more the shareholders will have to pay for bankruptcy or reorganization costs. Ceteris paribus, this has a knock-on effect on increasing the cost of the primary sources of funding above those of any nonfinancial institution. On the other hand, there is a compensatory effect for those firms that provide enhanced risk capital cushion, in that their cost of float ${ }^{13}$ will be lower than that of companies with much thinner cushions. In a perfect market, the cushion provided by enhanced capital requirements should make it cheaper to raise funds from policyholders than securities issued by non-financial institutions without such protection.

The nature of the insurers' assets funding has always been that of leveraging their book in the form of high premium to equity ratios. The insurers' risk $^{14}$ arises primarily from their funding arrangements. Since insurance companies issue policies to raise investment funds, their risk profiles mirror the policies issued. The nature of the risk profile is a derivative of the perils insured, scope of coverage, correlation among exposures, and the company's underwriting policy. Pricing of insurance policies is done in advance, using risk models that forecast the impact of perils insured during the policy period. Risk models can only do as much as their inputs, and their appropriateness depends on the cash flow $^{15}$ characteristics - among other factors. At the end of the underwriting year, ${ }^{16}$ the outcome, known in this case as the underwriting result, will determine the actual cost of funding.

The power to predict the cost of financing has been diminishing because of the emergence and severity of new risks such as mega-catastrophes and extreme terrorism events. For instance, prior to 2000, very few companies had incorporated multihurricane scenarios, or severe earthquakes or tsunamis in their portfolio of exposures.

${ }^{11}$ Mutenga and Staikouras (2004).

12 This is a measure used by A.M. Best in their Best Capital at Risk calculation in rating insurance companies.

13 The cost of float is a measure of what is actually paid out to policyholders relative to the funds paid in by them due to the pre-payment of insurance premiums. The term was first coined by Warren Buffett, Chairman of Berkshire Hathaway, and has been used as a key financial metric within the firm. The cost of float is defined as the underwriting result divided by technical reserves. Underwriting result is the net of what companies pay in claims over the premiums received. Technical reserves represent investment funds that belong to policyholders. Essentially, it is an alternative measure of quality, in the underwriting book, than the loss or combined ratios. For more discussion, see Mutenga and Staikouras (2004).

${ }^{14}$ Financial risk is defined as deviation from expected funding costs and return on investments due to the existence of adverse events.

${ }^{15}$ In this study, the term "cash flow" is broadly used to describe the amount of losses or level of exposure(s) that an insurance firm faces as a result of a given or its overall loss experience.

${ }^{16}$ For multi-period contracts, there is scope to readjust the outcome of the model. 
These natural disasters tend to contaminate portfolios constructed on the law of large numbers and the central limit theorem. Over the years, there has been a growing mismatch between predicted financing costs and the realised costs of capital, despite efforts to incorporate extreme events in loss models. Nowadays, the number and severity of catastrophic risks are increasing rapidly and becoming ever more unpredictable. All these have been evident in the general insurance indices, which underperformed the general stock indices 80 per cent of the times over the past 20 years. ${ }^{17}$ In order to reduce unpredictability in the cost of funding, reinsurance has been used to offload risk. But its efficiency has also been questioned over the years, leading to the development of alternative ways of sharing funding costs. Most of the new techniques follow the reinsurance model of structuring the funding cost arrangements.

The spread between the pricing of insurance contracts and the investment return is also important. Failure to meet expected margins may adversely affect the equity and subsequently the risk capital. In order to reduce the level of risk(s) faced by insurers, regulators have put a cap on leverage levels. Caps appear in the form of limitations on the premium to equity ratios that insurance companies can exploit. Since caps place limitations on the amount of premiums underwritten, reinsurance has traditionally been used, as a form of non-recourse capital, to provide additional premium volume capacity. Unlike equity, the funds provided through reinsurance do not create new claims on the assets of the firm, and hence do not participate on the residual value generated for shareholders. Its status along side equity, as a method of funding risk, gives it a distinct advantage over equity as far as the pecking order of risk financing is concerned. The reason being that it circumvents the pecking order of funding, in that it seeks to raise contingent funding through well-informed investors. Thus, reinsurance has traditionally been used to reduce leverage levels, without having to reduce the volume of business written. ${ }^{18}$ In this way, it can be seen as a capital restructuring route enabling firms to meet their capital structure targets by simply transferring a portion of premiums to a third party, which in turn would make the company compliant.

\section{The market for insurance risk}

Although the benefits of debt financing imply that most companies should follow a debt issuing policy to maximise firm value, Donaldson's ${ }^{19}$ pecking order hypothesis seems to describe corporate practices better. While financial economists have long suspected that corporate financing decisions may be guided by a pecking order, it was not until Myers ${ }^{20}$ and Myers and Majluf ${ }^{21}$ presented a clear theoretical rationale for the pecking order theory. That is, corporations prefer to finance growth with internally generated funds first, then contingent risk financing and transfer, followed by debt and lastly equity. The reason for that is that equity is a paid-in residual claim,

\footnotetext{
${ }^{17}$ Mutenga (2002).

${ }^{18}$ See Durbin (2001) for a survey.

19 Donaldson (1961).

${ }^{20}$ Myers (1984).

${ }^{21}$ Myers and Majluf (1984).
} 


\begin{tabular}{lll}
\hline Retention Based & Reinsurance Based & Capital Based \\
\hdashline$\ldots \ldots \ldots \ldots \ldots \ldots \ldots \ldots \ldots \ldots \ldots \ldots \ldots$ \\
Finite & Finite & Derivatives \\
Reserves & Traditional & Securitisation \\
Captives & & Contingent financing \\
\hline
\end{tabular}

Figure 1. Cash flow engineering instruments.

which means that equity holders have to bear the risk of cash flow volatility. Therefore, since equity is not a non-recourse source of funding, shareholders will demand a higher risk premium.

The nature of insurance business makes it very difficult to ascertain the level of actual losses within a financial year, even though calculated premiums account for a variety of scenarios. Instruments targeting underwriting risk reallocation have significantly contributed to the risk financing field. The evolution of these mechanisms provides a vivid picture of how (re)insurers have enhanced their knowledge to comprehend cash flow behaviour. Such instruments have sought to mitigate any negative externalities, given the practitioners' perception and understanding of insurance cash flows. Figure 1 presents the three broad classes of financing risk in the insurance business.

These are the main groups used in hedging/covering firm-wide risk according to the nature of cash flows they target. These cash flows are associated with the risk protection insurers provide against situations ranging from merely inconvenient to traumatic. We believe risk financing instruments should be able to bridge the gap between sound asset-to-liability ratios and the solvency threshold. The use of different risk financing channels in sourcing contingent capital aims to smooth the cost of capital, and in so doing lowers financing expenditures. For an effective and optimal risk management scheme, such instruments should target specific classes of cash flows. That is why it is difficult, through retention and reinsurance systems, to mitigate the negative impact arising from catastrophes. Retention and reinsurance-based techniques do not go far enough in satisfying the risk transfer requirements of cash flows occupying the upper tails of the loss distribution.

Based on the above discussion, it is therefore understandable that different risk financing channels should match different sections on the loss distribution. Losses on the tail of the loss distribution are best financed by capital market-based instruments. These instruments are bought with the sole purpose of alleviating the strain on capital and/or enhancing its role when depleted after a catastrophic event. They are efficient at financing the upper part of the loss distribution because vast amounts of capital are easily accessible, making it cheaper than accumulated reinsurance and retention-based equity. On the other hand, retention ${ }^{22}$ and reinsurance-based techniques are efficient in financing risks associated with higher probability of occurrence. Retention-based techniques are efficient at financing risk using the all-purpose equity supplied by

${ }^{22}$ The term "retention-based" stems from the fact that the original carrier retains risk in total or in part. 


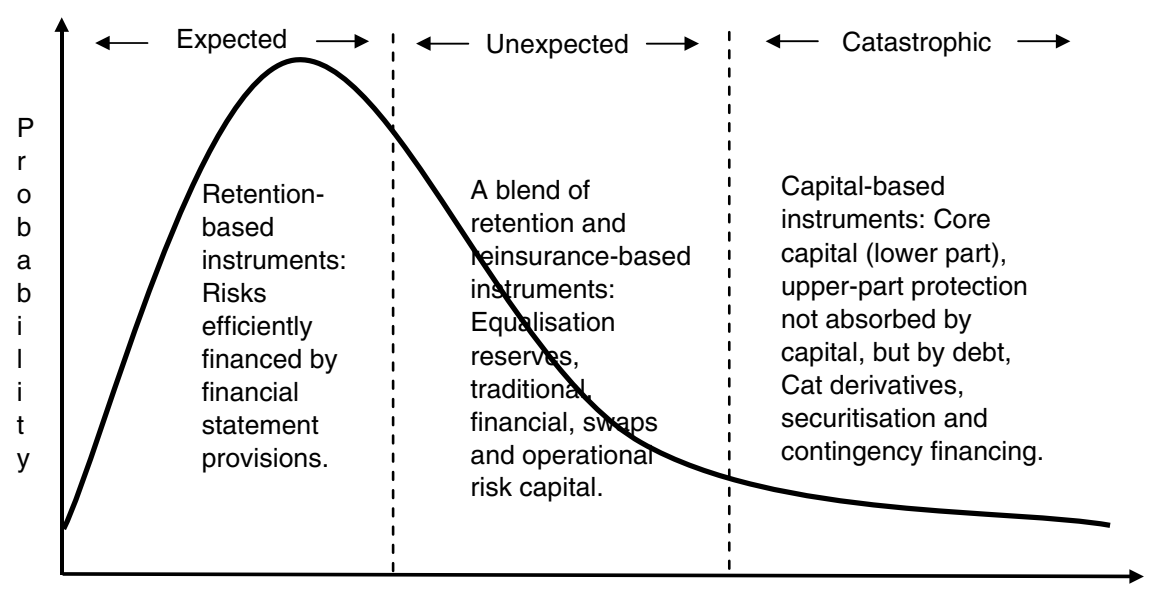

Magnitude of Loss

Figure 2. Efficient utilisation of insurance equity: A layered risk financing structure.

shareholders and accumulated from retained earnings. Reinsurance-based instruments are used to provide protection for cash flows occupying the unexpected loss region up to the tails of the loss distribution. Figure 2 matches the risk financing vehicles with different segments of a loss distribution.

Figure 2 is very intuitive since the second segmented line (maximum unexpected loss) mirrors the calculation of the capital at risk $^{23}$ (CAR) figure for any financial intermediary. This is actually the worst-case scenario where losses beyond this point will result in consuming the capital of the corporation. Thus, proper structuring of the risk financing process entails understanding of the specific characteristics at each loss layer (or risk tier), simply because such structures should recognise the particular underlying cash flow features. According to Lamm-Tennant and Weiss, ${ }^{24}$ it is important that the frequency of using these vehicles decline as one moves from one risk tier to the next. Actually, this has to do more with the efficiency and costs of using these instruments, rather than strictly matching their proposed risk tier. Cash flows on the tail of the distribution have low and uncertain loss probabilities, so the use of these instruments is not economically viable if the company is small. ${ }^{25}$ The main reason for the high cost structure is due to the paucity of credible data, which limits the level of our knowledge regarding these cash flows.

The aforementioned proposed risk financing structure is designed to reallocate risk to those who have the competitive advantage to bear it. At the same time, it enables those who seek to strengthen their financial position to source leveraged capital at

\footnotetext{
${ }^{23}$ For an excellent exposition and discussion of the quantitative aspects of financial risk management, see Dowd (1998).

${ }^{24}$ Lamm-Tennant and Weiss (1997).

${ }^{25}$ Froot (1999).
} 
reduced costs. The structure aims to stabilize risk portfolios through the enhancement of the cost of risk trading, lower default probabilities, and make contingent capital available while maintaining target financial structures. The intention is that risk financing should be able to release assets committed to liabilities and should reduce the cost of risk capital in sponsoring all-purpose equity.

\section{Conventional approaches in managing insurance risk}

Originally, the sharing of risk(s) among underwriters was accomplished through coinsurance wherein direct coverage was provided by more than one insurer. The phenomenon was and is still used in the London market as well as in other markets across the world, but less so in the U.S. The next step was the so-called reciprocity agreements in which insurers would reciprocate in the sharing of each other's risks. The first independent reinsurance firm, Cologne Reinsurance Company, was formed in Germany in 1846. Since then, financial markets in general and the insurance business in particular have come a long way to meet a variety of risk analysis and management platforms. The next few paragraphs will concentrate on the established channels of dealing with loss exposures.

\section{Retention-based techniques}

Retention is the primary technique of handling losses. In essence, the firm retains part or all of the losses that result from a given loss experience. Retention can be effectively used in a risk management ${ }^{26}$ framework when three conditions are met. First, losses are highly predictable; second, the worst-case scenario is of low severity; and third, it is the most effective treatment available. The perception of insurance cash flows, under this method, is different from a reinsurance perspective in that the retained cash flows are viewed as being (or should be) efficiently financed by all-purpose equity. Since the early 1990s, the level of retention, across major markets, has been increasing at a faster rate than that of the overall capacity limit, as shown in Figure 3. Interestingly, this has been happening despite the fall in the rate on line (ROL) ${ }^{27}$ since 1993.

Figure 3 also shows the importance of retention-based techniques in engineering cash flows. ${ }^{28}$ The level of retention is based, among other factors, on the firm's ability to sponsor equity to sustain any adverse movement in the insurer's capacity to deal with losses. It is noted, however, that risk retention is only done when the available allpurpose equity is adequate in sponsoring the risk(s) at hand. If a negative trend in the ROL index is interpreted as cheaper coverage, the intriguing reality is that it has not

${ }^{26}$ For a detailed discussion on insurance and risk management issues, the interested reader is referred to Rejda (1998).

${ }^{27}$ This is the standard insurance metric that tracks premium divided by coverage. It shows the average cost of buying analogous reinsurance coverage over a period of time. An increasing index shows that cedants are paying more on the same coverage, while an opposite trend is interpreted as cheaper coverage.

${ }^{28}$ Guy Carpenter (2005) reports that despite four storms in 2004 and an estimated USD23 billion of estimated industry losses, most of the Florida losses were, for the most part, retained within ceding company retentions. This had a minimal impact on reinsurers and subsequent reinsurance pricing. 


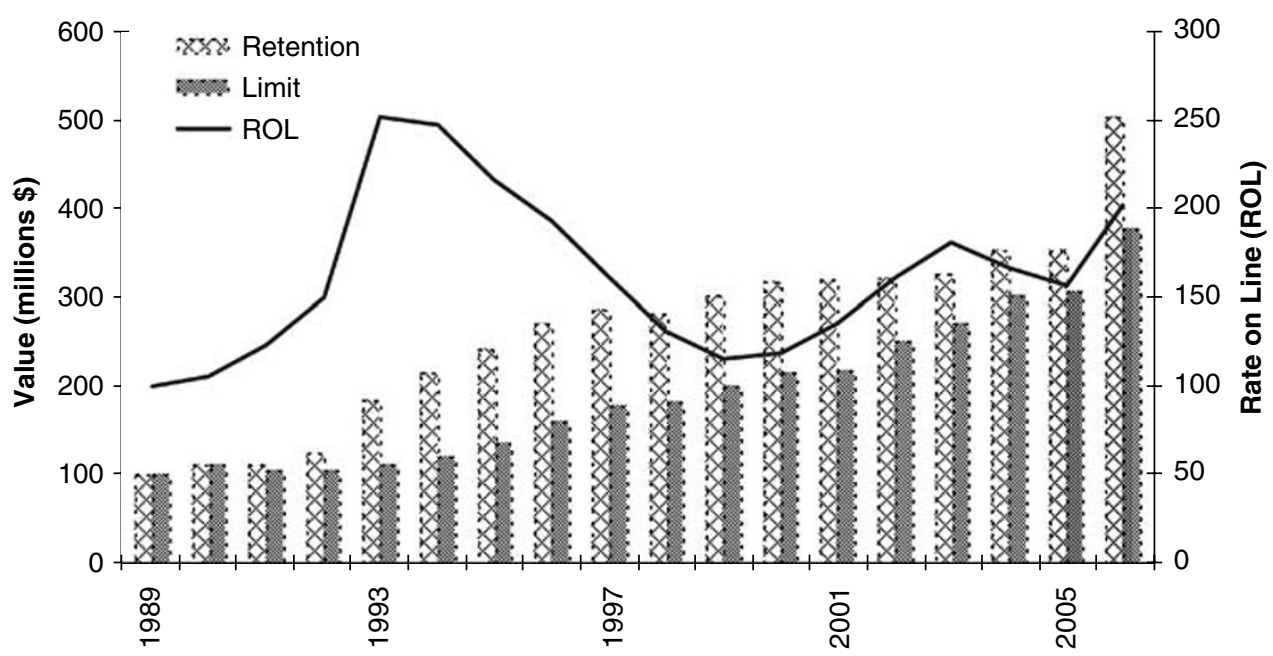

Figure 3. Global average retention, limits and ROL. Source: Guy Carpenter (2006)

been accompanied by increases in cessions. Therefore, it is not only the price of cover that matters, but also the efficiency with which all-purpose equity can finance risks within the expected loss tier. The cost of excessive or inadequate risk retention can be measured in terms of missed target cash flows over a period of time, say 5 years, because that is where most risk factors are captured.

Retention is essential in any risk-taking situation, and traditional reinsurance requires cedants to retain a portion of the risk portfolio before participation. ${ }^{29}$ Actually, retention is a means of reducing moral hazard and adverse selection arising from information asymmetry inherent in insurance cash flows. ${ }^{30}$ Thus, the critical role of retention can be recapitulated as: (a) it adds to the assessment of catastrophic protection and the impact it has on the rating awarded; (b) it serves as a disciplinary measure, required by those providing risk capital on higher layers, to encourage a firm to be more prudent in managing its loss portfolio (moral hazard argument); (c) it endorses the concept of value-added by retaining cash flows; (d) it signals the ability and/or level and/or suitability of capital to sponsor liabilities carried forward to settlement date (adverse selection); and (e) it contributes to the cost determination, as it is easier and cheaper to finance it.

Risk retention techniques can be implemented in two different ways: (a) executed within a portfolio and (b) engineered off-balance sheet under a separate financial setup. The decision to engineer retention within or outside a portfolio depends on the attributes of the $\operatorname{risk}(\mathrm{s})$ at hand, corporate strategy, business objectives, and

\footnotetext{
${ }^{29}$ It is also a requirement for securitisation to pitch a high retention in order to make catastrophe bonds tradable.

${ }^{30}$ Doherty and Posey (1997).
} 
profitability. The discussion so far is based on the retention done on the balance sheet. Engineering off-balance sheet structure aims to reap benefits that cannot be extracted when risks are actively retained within the portfolio. These benefits are related to taxexemption, production costs, financing flexibility, pricing efficiency, and development of new financing products. For instance, a captive is used to reinsure risks of the parent company in an offshore location (not always necessary), in order to arbitrage on tax and, in the process, to achieve an efficient equity-to-risk financing. With an integrated structure ${ }^{31}$ in mind, such schemes enhance corporate diversification and rationalise insurers' attitude towards advanced risk management.

\section{Reinsurance-based coverage}

Reinsurance-based techniques can be classified into two broad groups, those with a traditional flair and those that are financial in nature. Although reinsurance has been the main vehicle to finance underwriting risk, its nature has changed over the last 15 years. ${ }^{32}$ Nowadays, reinsurers are exposure underwriters rather than just reacting to occurrences of large losses, in that they are increasingly utilising catastrophe modelling techniques. The main forms of traditional reinsurance are proportional reinsurance composed of: facultative, quota share, and surplus share; and non-proportional reinsurance composed of: facultative, per risk, catastrophe, and aggregate excess of loss.

The cash flow structure targeted by reinsurance is that embedded with underwriting risk, which is the risk that the actual losses paid differ from those expected due to changes in the nature of $\operatorname{risk}(\mathrm{s})$, the stochastic nature of event(s) and/or the error in modelling losses. Froot et al. ${ }^{33}$ point out that hedging is mainly driven by the interaction between investment and financing considerations. Establishing a relation between the existing assets and cash flow behaviour is essential, as pre-existing assets determine the firm's capacity to contain risk. Reinsurance essentially targets the layer of the loss distribution below the tails that affects economic capital. But how far does reinsurance go in practise? The average attachment ${ }^{34}$ and exhaustion points (on a return-period basis) can draw a reliable picture. Using recent U.S. data, the average catastrophe programme attached at the 15-year payback period level and exhausted at 220-year level. ${ }^{35}$ This is how far reinsurance could finance the loss distribution, with the range above the 220-year level funded either by capital market-based instruments

${ }^{31}$ It is very important that all structures are carefully integrated in the strategy and management of the corporation involved. For a detailed discussion on the issues related to integrated risk management, see Doherty (2000) and Shimpi (2001).

${ }^{32}$ Cutler and Zeckhauser (1999).

${ }^{33}$ Froot et al. (1993).

${ }^{34}$ Attachment points indicate the level at which reinsurers are responsible for losses in "excess of loss" contracts. The higher the attachment point, the less likely the reinsurer will have to pay out claims (i.e. risk of loss goes down). For instance, after huge hurricane-induced losses in 2005, reinsurance supply has gone down and demand has gone up, and that means reinsurers can demand higher attachment points.

35 Guy Carpenter (2005, 2006). 
or left as unfunded policyholder surplus deficit. However, it is worth noting that the industry has begun modelling its exposures using events that normally would occur once-in-150-year, which subsequently has a direct effect on premiums. ${ }^{36}$

Reinsurance, as a means of managing spreads, ${ }^{37}$ can only effectively alter the loss distribution up to the level where the cost of contingent funds is optimal as compared to other sources of financing. The problem with reinsurance is that equity in sponsoring risks is also accumulated, putting it in the same class with all-purpose equity used to fund retentions. Therefore, it still faces inefficiencies encountered under retention-based techniques, because accumulating equity for an event occurring once in a hundred years is uneconomic and prohibitively expensive. Furthermore, reinsurance is traded on a piecemeal basis making it more costly than other risk financing methods. Evidence across the major insurance markets reveals that, due to modelling techniques used by reinsurers in pricing catastrophe risk, the ROL and loss on line indices have started bearing a close resemblance. ${ }^{38}$

On the other hand, finite risk reinsurance represents a combination of risk transfer and risk financing techniques by emphasising the time value of money. These instruments are used to cover underwriting and timing risks. The former has been discussed under reinsurance above, while the latter pertains to those risks resulting from erroneous expectations regarding the rapidity of loss settlement. Since loss payments may occur earlier than expected, insurers are exposed to liquidity risk and also suffer the loss of interest bearing capital, in the form of loss reserves. Moreover, finite risk reinsurers do assume market and credit risk for the primary insurer in circumstances where one or more traditional reinsurers are insolvent. These covers provide cash flows to an insurance company that can only effectively hedge exposures in the lower part of the unexpected section of the loss distribution. These instruments are usually Loss Portfolio Transfers (LPTs), Adverse Development Covers (ADCs), Finite Quota Shares (FQSs) and Spread Loss Treaty (SLT).

LPTs relieve the insurer of its existing obligations to pay losses already incurred on the book, by transferring these obligations to a third party in exchange for a premium. They are retrospective in nature, in that the transfer of liabilities is only for outstanding losses. The premium ceded is approximately equivalent to the net present value of the ceded loss reserves. The reinsurer charges a profit and cost margin for underwriting risks reflecting the timing and subsequent reserves assumed. In general, LPTs (a) provide a means of managing timing risk - relating to claims settlement over time; (b) lower the uncertainty of claim settlement patterns when it proves costly to the insurer; and (c) reduce the pressure on solvency margins, since they convert future investment income to current underwriting income. Insurers also use portfolio transfers when withdrawing from certain lines or closing peripheral activities to concentrate on the core business. This cash flow engineering technique has been useful in (a) bringing precision to planning, (b) facilitating mergers and acquisitions, and (c) controlling latent liabilities spiralling out of control. Equity release under this

\footnotetext{
${ }^{36}$ Verrall (2006).

${ }^{37}$ The spread is referred to the differences between the cost of funding and reinsurance.

${ }^{38}$ Guy Carpenter (2005).
} 
technique improves financing efficiency, reduces the cost of capital by alleviating pressure on components of the financial structure, and it makes cash flows left in the portfolio easier to manage.

ADCs provide protection against losses that have been incurred but not reported (IBNR) and for protection against inadequate loss reserves. The premium paid reflects the scope of the underwriting risk(s) assumed and takes into account the net present value of the loss payments expected during the term of the contract. In this case, the time value of money can be used to come up with a more cost-effective way of funding risk. ADCs also facilitate insurers' acquisitions/mergers since long latent claims can be partially protected. Considering a firm with liabilities that are difficult to assess, ADCs offer an information arbitrage to shareholders and rating agencies in that the company will trade the unknown for the known.

FQSs provide cover for the current/future underwriting years, by ceding a part of unearned premiums in return for commission. They are a result of the U.S. Statutory Accounting Principles, which allow for accruals of acquisition costs. ${ }^{39}$ FQSs can correct the inter-temporal reduction in equity by removing distortions on financial statements arising from volatile acquisition costs. Essentially, they are used on structures exhibiting annual variations in acquisition costs, which in turn significantly affect the return on equity. FQSs are a source of moral hazard and adverse selection, however, as the targeted risk is subjective, even though there might be safeguards of liability-linked sliding scale commission and specific limits on liability.

Our final risk engineering technique deals with underwriting risk and balances risk over time - effectively smoothing fluctuations in the financial structure. SLT derives from accumulation of bespoken annual premiums into a loss experience account over the whole term of the treaty (funded cover). Apart from being a reinsurance-based technique, it also has retention-based attributes in that interest income is credited to the ceding company, with the payment of losses and reinsurers' margin being paid from the experience account. The losses incurred are distributed over a number of years, with the result in the account each year determining the level of premiums to be paid, and which of the parties is liable to pay if the contract is in its last year.

\section{Securitisation of insurance risk via capital markets}

Back in the early 1980s, the term "risk management" had a more precise, but narrower, meaning than that witnessed 20 years later. The scarcity of resources in the insurance arena to cover extreme events has led market participants to explore alternative ways of financing risk. ${ }^{40}$ Today, capital markets offer a colossal pool of money to hedge financial risks and simultaneously enhance corporate values. ${ }^{41}$ Putting together these alternative risk financing programmes, however, can be costly since it

\footnotetext{
39 These are immediately accounted for under standard accounting principles.

${ }^{40}$ Jaffee and Russell (1997), Punter (2000), and Cummins et al. (2002).

${ }^{41}$ Swiss Re (2001).
} 
involves transaction costs and basis risk(s) which are often regarded as prohibitive. ${ }^{42}$ Risk is now a traded commodity stripped from the asset value and offered separately in modern capital markets. It is noticeable that extreme events are positioned at the tails of the loss distribution(s), which make risk capital expensive when funded by shareholders' capital. In this section, the paper explores some of the most commonly used vehicles ${ }^{43}$ in hedging financial risk.

The insurance market surplus before the 2001 WTC attacks was estimated at around $\$ 465$ billion, which is only a fraction of capital markets' capitalisation with volatility levels in a single day quoted around $\$ 75$ billion. Fluctuations of this magnitude do not affect the viability of the market. A similar loss in the insurance industry will reduce the industry surplus by a significant amount, given that competitive pricing is done in line with a normal loss year and usually conforms to the lowest corporate cost structures. Mutenga ${ }^{44}$ shows that both the reinsurance and the $\mathrm{P} \& \mathrm{C}$ markets have been underperforming, given the higher level of risk(s) in the insurance arena. The cost of capital required to finance all catastrophic risks is phenomenal. Providing such capital requires instruments that package these risks in such a way that the return profile matches the risk(s) involved. Based on the recent experience of risk exposures, Verrall ${ }^{45}$ raises an interesting long-term question: "how much cost is the industry prepared to bear before it denies insurance for climaterelated risks and seeks to pass responsibility to governments?"

\section{Debt forgiveness structures}

Catastrophe bonds (insurance-linked or Act of God bonds) have become very popular and both insurers and reinsurers typically issue them. CAT bonds pay high interest and provide a portfolio diversification mechanism for the investors involved. The latter stems from the fact that the occurrence of extreme events is stochastic and is not associated with financial markets' performance. Investors bear the risk of interest or principal variability when losses reach a pre-specified level documented in the bond offering. For instance, a CAT bond would pay $100 \times(1-L)$ on maturity, where $L$ reflects the loss rate. The required yield on these bonds incorporates a risk premium reflecting the market's expectations of the event's probability of occurrence. It is worth mentioning that the debt issued through these bonds cannot be used for investment purposes by the firm. Figure 4 illustrates the structure of a typical offshore CAT bond involving a U.S. insurer exposed to catastrophe risks.

${ }^{42}$ It is not very easy to change the existing risk management programme(s) of any insurer within a short period of time. There are some valid reasons (e.g. information deficiencies, basis risk, regulatory framework, information asymmetries, cost of changing existing structures, etc.) as to why traditional practises are followed. Nonetheless, the industry needs to be proactive and start thinking of ways to move forward and face the challenges of our fast changing world. Here, both the state and the regulators will have a vital role to play in transforming the current (re)insurance landscape.

${ }^{43}$ These are usually instruments that are derived from other instruments, hence the term derivatives. For a detailed exposition of financial risk management techniques, see Dowd (1998) and Doherty (2000).

${ }^{44}$ Mutenga (2002).

${ }^{45}$ Verrall (2006). 


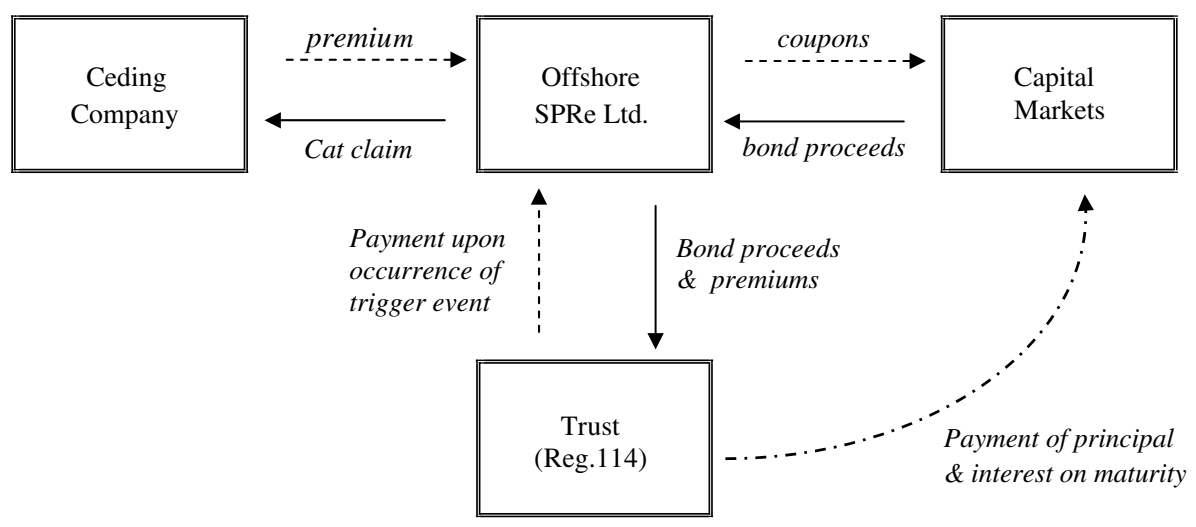

Figure 4. Offshore arrangement of catastrophe bonds.

The transaction in Figure 4 illustrates investors buying CAT bonds from the issuer, a special purpose reinsurer (SPRe), which simultaneously enters into a reinsurance contract with the cedent. The SPRe is formed specifically to serve this particular transaction, and forwards all the inflows to a Regulation 114 Trust, which in effect fully collateralises the obligations of the SPRe. If the qualifying event occurs, the SPRe will pay the reinsurance cover to the cedent and forward any balance of funds to investors as a return of capital. If there has been no catastrophe(s), coupon payments and principal are given back to investors. Unlike CAT options and reinsurance, these bonds avoid credit risk, as debt forgiveness is provided by capital markets. Essentially, what the bonds do is to turn the default risk (i.e. implicit default put) into an explicit embedded forgiveness option. ${ }^{46}$ Note that some bonds are traded as principal protected, while others place principal at risk. The appendix, at the end of the paper, provides some statistics for the use of these instruments over the last 10 years.

Finally, looking at the U.S. insurance market, it is interesting to note that since the inception of these hedging tools, all deals undertaken by or for a U.S. insurer were actually offshore (Bermuda, Cayman, etc.). The latter stems mainly from the regulatory, legal, and tax uncertainty related to these transactions. Over the last few years, in the U.S., there have been efforts (the INEX and Protected Cell Company approach) aiming to address these uncertainties and facilitate a suitable onshore environment. Further discussion on this topic, however, is beyond the scope of the present study.

\section{Swap transactions}

A swap agreement involves two or more risk-bearers assuming partial and/or reciprocal liability for a defined component of each other's risk. ${ }^{47}$ CAT derivatives are

\footnotetext{
${ }^{46}$ Doherty (2000).

${ }^{47}$ Through these reciprocity agreements, one could easily argue that the participants achieve geographical diversification of insurance losses. The early risk exchange mechanism was done in London at a Lloyd's coffee shop where traders came and posted or advertised their risks on a notice board. Assessments were
} 
traded publicly on risk transfer markets, such as those of New York (CATEX), Bermuda (BCT), internet-based weather derivatives exchange (I-WEX), as well as privately over the counter (OTC). CATEX and CATEX Bermuda ${ }^{48}$ began operating in early 1996 and 1997 as reinsurance intermediaries facilitating reinsurance transactions - licensed by the New York Insurance Department and Bermuda Parliament, respectively. The CATEX is a worldwide trading system for the exchange of risk by insurers and other financial firms. Under the CATEX mechanism, members buy, sell, and/or exchange insurance risk and trade index-based insurance derivatives. Risk bearers and their brokers negotiate and complete trades through an electronic communication system, and these trades are registered, published, and archived with CATEX. Risks are exchanged on a risk-for-premium or risk-for-risk basis with rights and obligations clearly defined.

Their risk-spreading feature protects the insurer's capital and surplus in case of a major catastrophe, and reduces the firm's value at risk for particular events. CATEX facilitates flexibility in risk financing by providing an opportunity for insurers to adjust and rebalance their risk portfolios on a real-time basis in response to market forces. ${ }^{49}$ This new distribution channel reduces risk distribution costs, when compared with the piecemeal reinsurance approach, and acts as a way of obtaining coverage for risks that are difficult to place. It also allows prompt and easier analysis of transactional information by company underwriters.

A close look at these transactions reveals that their capital accumulation characteristics are similar to those under reinsurance. Thus, it is not a pure riskbearing facility, as the exchange of risk between subscribers is treated as a reinsurance transaction.$^{50}$ It is also worth mentioning that most of the participating companies are from the insurance market. That is, an undiversified insurance surplus portfolio is being used to fund these risks, making capital generated from this market suitable only for middle layers of the loss distribution. The nature of subscribers in this market makes the funding of risk in the upper layers inefficient, because surplus generation is done through the accumulation of equity.

\section{Insurance futures}

In the early 1990s, the CBOT offered catastrophe futures instruments for the insurance market. ${ }^{51}$ Insurance futures were the first instruments to be introduced covering

done on site and risk acceptance communicated by indication of proportion assumed and a signature at the bottom of the sheet. However, insurance market inefficiency structure was incorporated into the distribution system making Lloyd's more of a reinsurance market than a swap market. If such a mechanism were maintained, we would not be talking about the revolutionary catastrophe trading exchanges nowadays.

${ }^{48}$ The Bermuda Commodities Exchange that was trading cat-options using the Guy Carpenter Catastrophe Index (GCCI) ceased trading in 1999.

49 Sweeney et al. (1997).

${ }^{50}$ Existing insurance statutory accounting practices are utilised to record CATEX trades.

${ }^{51}$ For more information on catastrophe insurance, see Cummins and Geman (1995), Magnan (1995), Kielholz and Durrer (1997), Kleindorfer and Kunreuther (1999), Lewis and Murdock (1999), Doherty (2000), Aase (2001), Froot (2001), and Zanjani (2002). 


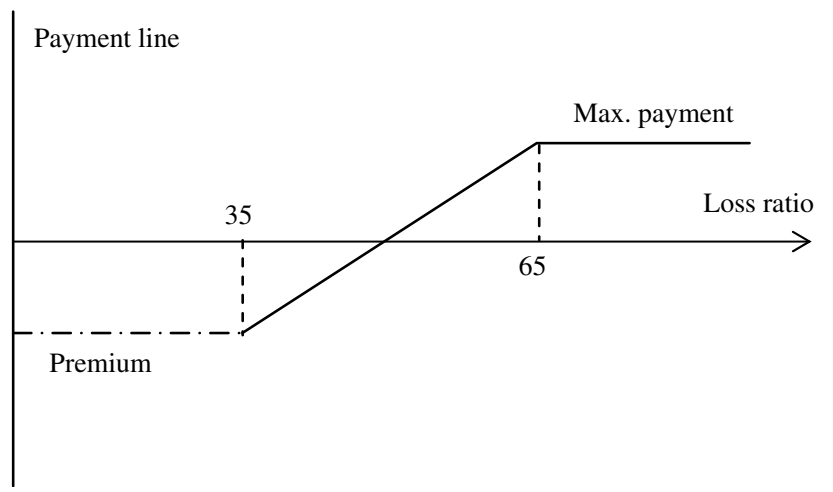

Figure 5. Payoff profile of a CAT call spread option.

health, homeowners, and automobile physical damages. The settlement price is based on an index calculated by Insurance Services Office. The index is based on reported incurred claims, for 22 insurers, on specific perils, which is divided by premiums earned to produce the loss ratio. Then, the payoff on the insurance futures is determined by the product of the loss ratio (incurred losses to premiums earned) and the nominal value of the contract $(\$ 25,000)$. The difference between the expected and the actual value of the loss ratio determines the profits (when ratio increases) or losses (when ratio decreases) on such transaction. D'Arcy and France ${ }^{52}$ and Harrington et $a l .{ }^{53}$ provide a detailed description of these contracts and discuss their technical aspects.

\section{Catastrophe options}

For a premium, the (re)insurer can also buy call spread options to protect against major catastrophes. Call spreads provide protection against a range of loss ratios (e.g. from 35 to 65 per cent) that may incur as a result of an extreme event(s). If the ratio ends up below the lower threshold, the insurer loses the premium paid, while anything above the upper limit is capped at this rate. A closer look at these contracts reveals that they are simply a duplication of being long on a call option with a strike price at 35 per cent, and being short on a put option with exercise price at 65 per cent. Assuming that the spreads are used by an insurer, then they can be constructed so that the strike prices are analogous to reinsurance payments. Cummins et al. $^{54}$ provide empirical evidence from the Florida hurricanes in support of these instruments to effectively hedge catastrophe exposures. The basic idea of a spread's payments is illustrated in Figure 5.

\footnotetext{
${ }^{52}$ D'Arcy and France (1992).

${ }^{53}$ Harrington et al. (1995).

${ }^{54}$ Cummins et al. (2004).
} 
On 29 September 1995, the CBOT replaced the insurance futures with a new product, namely the Property Claim Services (PCS) options. The contracts behave like stop-loss reinsurance, but the underlying portfolio is the risk to the industry or a portion of the industry in the U.S. These options are written on nine loss ratios calculated by the PCS. The PCS is an independent firm to which the industry reports claims. Since 1949, PCS has been providing estimates of catastrophe losses that are commonly accepted as the most reliable values available. Two characteristics of the PCS are the loss and development (or estimation) periods. The former refers to the time during which an extreme event must occur for resulting losses to be included in the index, while the latter is the time (6- or 12-month) after the loss period during which PCS estimates continue to affect the indices. The estimation period is crucial, as it could take months to settle losses as a result of a catastrophe. Finally, the PCS options offer a small cap contract (for losses up to USD20 billion) and a large cap contract (for losses from $\$ 20$ billion to $\$ 50$ billion).

\section{Contingent equity}

Market realities corroborate that it is usually difficult and expensive for a corporation to raise funds when its own capital is wounded. Investment banks routinely offer simple forms of contingent financing in the form of letters of credits and revolving credit facilities. The best way to protect the value embedded in a firm is to prearrange equity to be put at favourable rates, when a financially impairing event occurs. For instance, an insurer is assured that after a natural catastrophe, which reduces the surplus and the firm's credit standing, the company will be able to procure capital up to the agreed limits to help refinance its business. Thus, this sort of financing redresses the balance between equity and debt, and the potential embedded in the firm's structure could be realized. This kind of circularity is known as the feedback effect ${ }^{55}$ that is, the catastrophe hits the equity, which in turn triggers the exercise of the hedging device that restores the stock's value.

Contingent capital, ${ }^{56}$ in its simplest form, is a put option to raise funds, subject to certain conditions. That is, should a pre-specified event take place, the firm has the right to sell its own securities at the strike price for a fixed period of time ${ }^{57}$ Contingent capital comes also in the form of a reverse convertible debt instrument (RCDI), where debt is converted to equity when the qualifying event occurs. In either case, the firm has also the added advantage of retaining the ability to raise capital in alternative

55 Doherty (2000) refers to the particular phenomenon as the "apparadox", which is a portmanteau word resulting from the combination of words "apparent" and "paradox".

${ }^{56}$ Aon Re Inc. and Centre Reinsurance first introduced the contingent equity product to the market under the trade name CatEPuts (Catastrophic equity puts). Deals in RLI \& Horace Mann and the first syndicated deal followed this with the option writers in the La Salle Re being European Re (lead investor), Allianz, Aon \& CAN; the equity was in the form of convertible preferred shares.

${ }^{57}$ For those familiar with the derivatives market, these instruments have similar characteristics to the knock-in option and multi-trigger products which both provide cash to the firm. The difference with the former is that the risk related to a contingency capital is different from that of the underlying asset, while the difference with the latter is that the contingency capital does not transfer the risk and results in a new paid-up capital. 


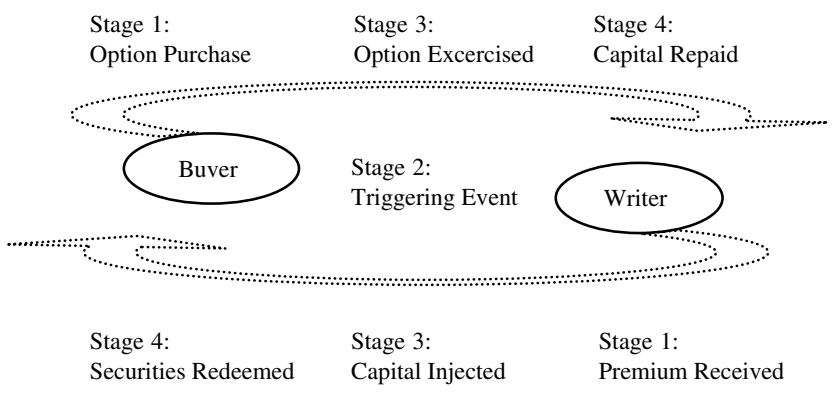

Figure 6. The process of raising contingent capital.

markets. When fundraising refers specifically to equity, then these instruments are also known as CatEPut. Capital raised through equity puts or RCDI is treated as equity, which means it adds directly to surplus, providing a stronger balance sheet and protection at a cost that is lower than a traditional secondary equity offering, and competitive when compared to a top layer catastrophe cover. ${ }^{58}$ Figure 6 illustrates the way contingent capital deals operate.

The above process is a multi-year deal between, say, an insurer and a reinsurance firm. (Re)insurers are in the business of undertaking risk, but they do not hedge them; they usually diversify them. The buyer pays the option premium in exchange for the equity put. The premium could be spread over the term of the option and is taxdeductible. For the option to be exercised, two contingencies should surface: (a) the extreme event occurs and (b) the stock price falls below the strike price, that is, the option is "in the money". This is when the buyer exercises the right to issue new shares, at a pre-determined price, to recapitalise its balance sheet. From this time, the capital provider (option writer) starts receiving the dividends (or interest depending on the type of capital raised) on the equity supplied. The next step is for the buyer to redeem the shares and repay the capital.

Like any other capital market instrument, contingent capital involves a few risks worth mentioning. Some of these risks could enter the contingent capital agreement in the form of clauses ${ }^{59}$ to add extra layers of security. The buyer loses its premium paid, if the rare event does not occur within the option period. The severity of the event could be substantial, resulting in the bankruptcy of the buyer and leaving the writer with no capital repayment. Perfect hedging is not guaranteed, as basis risk is present as in any other derivatives product. ${ }^{60}$ Exposure to credit risk is another factor worth

${ }^{58}$ In the case of La Salle Re, a Bermuda reinsurer writing global-based risks provided a $\$ 100$ million contingent equity facility following either a single catastrophic event exceeding \$200 million or an aggregation of \$250 million from smaller catastrophes, at a cost of \$2.35 million p.a. for three years.

${ }^{59}$ In the investment banking industry, it is common to include numerous covenants when loan financing takes place. In this case, one party could request a precondition of minimum capital before the option is exercised or monitor the buyer's activities to ensure the writer's interests are protected.

${ }^{60}$ This comes in contrast to the reinsurance-based approach where basis risk is reduced, while moral hazard increases. 
considering that affects both parties involved. Finally, the choice of the right instrument is vital in order to match the corporation's long-term strategy, as well as the cash flows and financing needs in the post-loss phase.

Apart from equity financing, contingency capital can also take the form of debt or hybrid security financing. For instance, banks and insurers can deploy regulatory and solvency capital respectively, while non-financial firms can resort to their liquid debt. Contingent capital is not a risk transfer product, but a refinancing vehicle. As previously discussed, it has features of an option, yet the underlying asset is corporate capital. Understandably, it is a combination of insurance and capital market techniques, and is tailor-made to the parties involved. In summary, these instruments offer: partial hedging, credit enhancement, post-loss liquidity, low cost of capital, and mitigate underinvestment and asset substitution problems. Contingent capital does not smooth accounting earnings; like finite reinsurance, it smoothes cash flows.

\section{Discussion and closing remarks}

One of the issues the insurance industry faces is that it has not yet made use of the new techniques to the extent that might seem appropriate. Although (over-)reliance on reinsurance and conventional risk management approaches has so far proved efficient, it is time for the industry to think about the sufficiency of these channels in our rapidly changing world. At the same time the level of capitalisation in the U.S. reinsurance industry, in 1998, stood at a net premium written to surplus ratio of 0.67 - meaning sizeable capital supporting premiums. In recent years, the figure has further elevated and passed the 0.85 level. ${ }^{61}$ But if, in this sense, the industry is "overcapitalised", then why are insurers still concerned? The answer is quite obvious and adeptly presented by Froot $^{62}$ who points out the distinctiveness of the catastrophe exposure and the expensiveness of funds on the upper tail of the distribution. It is also true that financial markets, along with their risks, have changed dramatically as a result of globalisation, advances in technology and pushing the frontier of knowledge beyond expectations.

The concern with the conventional insurance coverage, either reinsurance or retention, is that it does not totally transfer risk. The insurer will have to pick up losses when a counter-party defaults (credit exposure), while amassed capitalisation is not suitable for risks embedded in the upper-tail of the loss distribution. The capacity of the property catastrophe reinsurance market varies considerably across markets and is not even enough to cover the simultaneous occurrence of extreme events. If large insurance capacity is withdrawn, due to the risk exposures becoming unbearable, then government intervention would be required to provide coverage for risks the market is no longer prepared to support. This clearly illustrates the mismatch and/or inefficiency between hedging policies and underlying cash flows at the end of the loss distribution. The overall cost of capital in the industry is of concern, and action needs to be taken to align the insurance performance with other sectors in the financial services industry.

\footnotetext{
${ }^{61}$ A.M. Best (2006).

${ }^{62}$ Froot (1999).
} 
The use of the all-purpose equity and reinsurance-based instruments has bedevilled the industry with the problem of under-funding due to the situation just discussed.

The complexity of modern risk financing devices, which makes it difficult for small insurers to use them, is one of the reasons attributed to their slow growth. In the 1990s, there were difficulties in the supply of reinsurance with the ROL index hitting new highs. This prompted the development of other ways of financing cat-risks so as to supplement existing capacity. The trend, at that time, did not envisage difficulties inherent within the regulatory, tax, and accounting structures. The favourable regulatory and accounting requirements, in the cat-bond market, have taken a long time to develop, hence the dominance of traditional indemnity-based routes. Even though regulators in the U.S. and EU are aiming to be proactive, it will take some time until a way of determining how much capital is released for non-indemnity instruments is agreed upon.

At the same time, the special purpose vehicle (SPV) debacles of Enron (2001) and AIG finite insurance (2005) have not provided the necessary support. The number of bonds issued in 2001 dropped to their lowest level. While this cannot be named as the main reason, an illiquid capital market environment was also a factor, with investors shifting towards high-grade bonds. The AIG case has certainly contributed to changes in the regulatory and accounting requirements of these instruments that do not favour their growth. Since SPVs are vital for cat-bonds, the requirement to increase their transparency has also led to increased cost of issuing bonds. On the other hand, tax reduction of SPVs in Europe and the U.S., by means of tax pass-through, may boost their popularity.

Creating an instrument that is transparent and attractive to investors requires the use of an index or parametric factors, but these instruments do come with basis risk. At the same time, index-based instruments do not receive the same credit on liabilities (in terms of capital release) that reinsurance and indemnity-based instruments enjoy, although they are favoured by investors. One way of reducing the complexity of catbonds is through tranching, a method that has been used in securitising mortgage cash flows, but still yet to be widely utilised by insurers. A development in this direction will certainly help, along with regulatory changes and the growth in life securitisation. As regulatory, tax, and accounting laws mature, we will see a surge in the growth of alternative risk transfer techniques.

It is already a theoretical and empirical reality that no single approach will suffice to predict insurance losses, and no single instrument will be able to offer complete compensation. The synthesis of the newly available risk financing vehicles, however, opens new routes to insurers. Blending techniques will not only optimise the firm's risk bearing position(s), but will also improve profitability and remove unnecessary pressure on equity. Modern insurers are indirectly led to look carefully at their portfolio of risks, their cash flows, as well as their distinctive asset-liability structures. They are compelled to form a realistic view of their business exposures, maintain flexibility - in terms of choice and diversification - and seriously account for any changes in their cost of capital in order to be competitive. Their sources of financing (risk/investments) are directly affected by the nature of the risks they undertake, which in turn both fully explain the underlying cash flows and the insurer's cost of capital. 
This study surveys the way risk is arbitraged through the engineering of insurance cash flows. The latter is described as a process that starts with the clear understanding of risk levels, the segmentation of the loss distributions, and the identification of pertinent ways of financing risk. The paper illustrates that cash flow engineering grants a range of solutions, as long as risk segments are matched to cash flows - with amenable equity accumulation structures in place. Risk segmentation is a virtue, as it allows an insurance company to match specific risk attributes with equity that is efficient in financing risk at specific layers. The goal of any risk consumption exercise is to maximise the long-term risk-adjusted return to shareholders. Unrealistic assumptions regarding risk bearing may overstretch the financial capability of an insurance company, while an overcautious stance on risk may result in loss of revenues and suboptimal positions.

A number of risk management innovations have been discussed and analysed. Some of them simply seek to place a catastrophe instrument directly with investors. That is, nowadays investors can "gamble" with the occurrence of a specific event, for example floods in the U.K. or hurricanes in the Gulf of Mexico. Hedging techniques are related to contracts that are executed based on the occurrence and severity of a qualifying catastrophe, while financing risk(s) can be achieved through a post-loss recapitalisation of the firm via capital markets. Finally, the paper addressed the feedback effect of those hedging devices, where the value of the firm falls, triggering the exercise of a contract, which in turn "restores" share prices. In the end, the effectiveness of each risk management programme will be measured by the extent to which a payoff stays over and above the knockout barrier, and the gradients of the upside and downside payoffs.

\section{References}

Aase, K.K. (2001) 'A Markov model for the pricing of catastrophe insurance futures and spreads', Journal of Risk and Insurance 68: 25-49.

Achleitner, P.M., Biebel, J.H. and Wichels, D. (2002) 'Does the WTC matter for the investment policy of $\mathrm{P} / \mathrm{C}$ insurance companies?', The Geneva Papers on Risk and Insurance - Issues and Practice 27(2): 275-282.

A.M. Best (2006) Best's Aggregates and Averages - United States and Canada P/C Edition, A.M. Best Company Inc., Oldwick, NJ.

Arrow, K.J. (1963) 'Uncertainty and the welfare economics of medical care', American Economic Review 53: 941-973.

Cummins, J.D., Doherty, N.A. and Lo, A. (2002) 'Can insurers pay for the "Big One"? Measuring the capacity of the insurance market to respond to catastrophic losses', Journal of Banking and Finance 26: $557-583$.

Cummins, J.D. and Geman, H. (1995) 'Pricing catastrophe insurance futures and call spreads: An arbitrage model', Journal of Fixed Income 4 (March): 46-57.

Cummins, J.D., Lalonde, D. and Phillips, R.D. (2004) 'The basis risk of catastrophe-loss index securities', Journal of Financial Economics 71: 77-111.

Cummins, J.D., Phillips, R.D. and Smith, S.D. (1997) 'Corporate hedging in the insurance industry: The use of financial derivatives by US insurers', North American Actuarial Journal 1: 13-49.

Cutler, D. and Zeckhauser, R. (1999) 'Reinsurance for catastrophes and cataclysms', in K. Froot (ed) The Financing of Catastrophe Risk, Chicago: The University of Chicago Press, pp. 233-269.

D'Arcy, S.P. and France, V.G. (1992) 'Catastrophe futures: A better hedge for insurers', Journal of Risk and Insurance 59: 575-600. 
Doherty, N.A. (2000) Integrated Risk Management, London: McGraw-Hill.

Doherty, N.A. and Dionne, G. (1993) 'Insurance with undiversifiable risk: Contract structure and organizational form of insurance firms', Journal of Risk and Uncertainty 6: 187-203.

Doherty, N.A., Lamm-Tennant, J. and Starks, L. (2003) 'Insuring September 11th: Market recovery and transparency', Journal of Risk and Uncertainty 26: 179-199.

Doherty, N.A. and Posey, L.L. (1997) 'Availability crises in insurance markets: Optimal contracts with asymmetric information and capacity constraints', Journal of Risk and Uncertainty 15: 55-80.

Doherty, N.A. and Schlesinger, H. (2002) 'Insurance contracts and securitization', Journal of Risk and Insurance 69: 45-62.

Donaldson, G. (1961) Corporate Debt Capacity, Cambridge, MA: Harvard University Press.

Dowd, K. (1998) Beyond Value at Risk: The New Science of Risk Management, London: Wiley \& Sons.

Durbin, D.L. (2001a) 'Managing natural catastrophe risks: The structure and dynamics of reinsurance', The Geneva Papers on Risk and Insurance - Issues and Practice 26(2): 297-309.

Durbin, D.L. (2001b) 'Hedging natural catastrophe risk in developing countries: Comment', The Geneva Papers on Risk and Insurance - Issues and Practice 26(3): 386-388.

Freeman, P.K. (2001) 'Hedging natural catastrophe risk in developing countries', The Geneva Papers on Risk and Insurance - Issues and Practice 26(3): 373-385.

Froot, K.A. (1999) The Financing of Catastrophic Risk, Chicago: The University of Chicago Press.

Froot, K.A. (2001) 'The market for catastrophe risk: A clinical examination', Journal of Financial Economics 60: $529-571$.

Froot, K.A., Scharfstein, D.S. and Stein, J.C. (1993) 'Risk management: Coordinating corporate investment and financing policies', Journal of Finance 48: 1629-1658.

Gollier, C. (1992) 'Economic theory of risk exchanges: A review', in G. Dionne (ed) Contributions to Insurance Economics, Boston: Kluwer Academic Press.

Goshay, R.C. and Sandor, R.L. (1973) 'An inquiry into the feasibility of a reinsurance futures market', Journal of Business Finance 5: 56-66.

Guy Carpenter (2005) The World Catastrophe Reinsurance Market, Guy Carpenter \& Co., Inc., New York.

Guy Carpenter (2006) The World Catastrophe Reinsurance Market, Guy Carpenter \& Co., Inc., New York.

Harrington, S.E., Mann, S.V. and Niehaus, G. (1995) 'Insurer capital structure decisions and the viability of insurance derivatives', Journal of Risk and Insurance 62: 483-508.

Jaffee, D. and Russell, T. (1997) Catastrophe Insurance When Capital is Limited: A Comparison of Public and Private approaches, Pacific Rim Insurance Conference, Singapore, 4-6 September 1997.

Jaffee, D. and Russell, T. (2002) Extreme Events and the Market for Terrorist Insurance, NBER Insurance Conference, Boston, MA, 18 January 2002.

Kielholz, W. and Durrer, A. (1997) 'Insurance derivatives and securitization: New hedging perspectives for the US CAT insurance market', The Geneva Papers on Risk and Insurance - Issues and Practice 82: 3-16.

Kleindorfer, P. and Kunreuther, H. (1999) 'Challenges facing the insurance industry in managing catastrophic risks', in K.A. Froot (ed) The Financing of Catastrophe Risk, Chicago: The University of Chicago Press, pp. 149-189.

Lamm-Tennant, J. and Weiss, M.A. (1997) 'International insurance cycles: Rational expectations/ institutional intervention', Journal of Risk and Insurance 64: 415-439.

Lewis, C. and Murdock, K. (1999) 'Alternative means of redistributing contracts against catastrophic loss', in K.A. Froot (ed) The Financing of Catastrophe Risk, Chicago: The University of Chicago Press, pp. 51-85.

Magnan, S. (1995) 'Catastrophe insurance system in France', The Geneva Papers on Risk and Insurance Issues and Practice 77: 474-480.

Merton, R. and Perold, A. (1993) 'Theory of risk capital in financial firms', Journal of Applied Corporate Finance 6: 16-32.

Mutenga, S. (2002) Risk Management for Property - Casualty insurance companies, Ph.D. Thesis, Cass Business School, City University, London.

Mutenga, S. and Staikouras, S.K. (2004) 'Insurance companies and firm-wide risk: A barrier option approach', Journal of Insurance Research and Practice 19: 62-70.

Mutenga, S. and Staikouras, S.K. (2007) Catastrophe insurance: Facts and data over the recent years, Working paper, Cass Business School, City University, London. 
Myers, S.C. (1984) 'The capital structure puzzle', Journal of Finance 39: 575-592.

Myers, S.C. and Majluf, N. (1984) 'Corporate financing and investment decisions when firms have information that investors do not have', Journal of Financial Economics 13: 187-221.

Punter, A. (2000) 'New solutions for the financing of risk', Journal of Insurance Research and Practice 15: $28-39$.

Raviv, A. (1979) 'The design of an optimal insurance policy', American Economic Review 69: 84-96.

Rejda, G.E. (1998) Principles of Risk Management and Insurance, Boston: Addison Wesley.

Saunders, A. and Cornett, M.M. (2006) Financial Institutions Management: A Risk Management Approach, London: McGraw-Hill.

Shimpi, P.A. (2001) Integrating Corporate Risk Management, London: Texere.

Staikouras, S.K. (2006) 'Business opportunities and market realities in financial conglomerates', The Geneva Papers on Risk and Insurance - Issues and Practice 31(1): 124-148.

Sweeney, J., Sonlin, S. and Correnti, S. (1997) 'Multi-currency asset-liability analysis in the insurance industry', in W. Ziemba and J. Mulvey (eds) Worldwide Asset and Liability Modeling, Cambridge: Cambridge University Press.

Swiss Re (2001) 'Capital market innovation in the insurance industry, Sigma no. 3/2001: 37.

Swiss Re (2002) 'Natural catastrophes and man-made disasters in 2001: Man-made losses take on a new dimension, Sigma no. 1/2002: 24.

Verrall, R. (2006) 'Climate change: Threat or opportunity?', European Business Forum 27(Winter): $17-18$.

Zanjani, G. (2002) 'Pricing and capital allocation in catastrophe insurance', Journal of Financial Economics 65: 283-305.

\section{Appendix: Statistical Figures for Catastrophe Bonds}

Since cat-bonds were first issued in 1997, their growth was slow until 2002, but 2006 witnessed an 80 per cent growth rate. U.S. perils have been a problem for insurers and it is no wonder they have the biggest share of bonds issued, with European windstorms coming second, and Japanese perils third. The usage of cat-bonds by insurers has seen a resurgence post Katrina, exceeding amounts raised by reinsurers for the first time. These bonds have targeted perils that are responsible for contaminating insurance portfolios and reduce the predictability of expected losses. If this is to continue, the use of cat-bonds in financing risk will increase.

Panel A. Catastrophe bonds issued by number and amount

\begin{tabular}{lcc}
\hline Year & $\begin{array}{c}\text { Number of issues } \\
\text { Risk capital issues } \\
\text { (\$ millions) }\end{array}$ \\
\hline 1997 & 5 & 633.0 \\
1998 & 8 & 846.1 \\
1999 & 10 & 984.8 \\
2000 & 9 & $1,139.0$ \\
2001 & 7 & 966.9 \\
2002 & 7 & $1,219.5$ \\
2003 & 7 & $1,729.8$ \\
2004 & 6 & $1,142.8$ \\
2005 & 10 & $1,991.1$ \\
2006 & - & $3,300.0$
\end{tabular}


(continued)

\begin{tabular}{|c|c|c|c|c|c|c|}
\hline Year & US earthquake & $\begin{array}{c}\text { US } \\
\text { hurricane }\end{array}$ & $\begin{array}{l}\text { European } \\
\text { windstorm }\end{array}$ & $\begin{array}{c}\text { Japanese } \\
\text { earthquake }\end{array}$ & $\begin{array}{c}\text { Japanese } \\
\text { typhoon }\end{array}$ & Other ${ }^{\mathrm{a}}$ \\
\hline 1997 & 112.0 & 395.0 & 0.0 & 90.0 & 0.0 & 36.0 \\
\hline 1998 & 145.0 & 721.1 & 0.0 & 0.0 & 80.0 & 45.0 \\
\hline 1999 & 327.8 & 507.8 & 167.0 & 217.0 & 17.0 & 10.0 \\
\hline 2000 & 486.6 & 506.5 & 482.5 & 217.0 & 17.0 & 129.0 \\
\hline 2001 & 696.9 & 551.9 & 431.9 & 150.0 & 0.0 & 120.0 \\
\hline 2002 & 799.5 & 476.5 & 334.0 & 383.6 & 0.0 & 0.0 \\
\hline 2003 & 803.8 & 416.1 & 474.1 & 691.2 & 277.5 & 100.0 \\
\hline 2004 & 803.3 & 660.8 & 220.3 & 310.8 & 0.0 & 0.0 \\
\hline 2005 & $1,269.0$ & 994.0 & 830.1 & 138.0 & 0.0 & 405.0 \\
\hline Total & $5,443.9$ & $5,229.7$ & $2,939.9$ & $2,197.6$ & 391.5 & 845.0 \\
\hline
\end{tabular}

Panel C. Catastrophe bonds transactions by sponsor type (\$ millions)

\begin{tabular}{|c|c|c|c|c|c|c|}
\hline \multirow[t]{2}{*}{ Year } & \multicolumn{2}{|c|}{ Insurer } & \multicolumn{2}{|c|}{ Reinsurer } & \multicolumn{2}{|c|}{ Corporate } \\
\hline & Amount & Number & Amount & Number & Amount & Number \\
\hline 1997 & 521.0 & 4 & 112.0 & 1 & 0.0 & 0 \\
\hline 1998 & 575.0 & 4 & 271.1 & 4 & 0.0 & 0 \\
\hline 1999 & 460.0 & 4 & 424.8 & 5 & 100.0 & 1 \\
\hline 2000 & 469.0 & 4 & 670.0 & 5 & 0.0 & 0 \\
\hline 2001 & 150.0 & 1 & 816.9 & 6 & 0.0 & 0 \\
\hline 2002 & 195.0 & 2 & 849.5 & 4 & 175.0 & 1 \\
\hline 2003 & 730.0 & 3 & 768.0 & 3 & 231.8 & 1 \\
\hline 2004 & 600.0 & 3 & 542.8 & 3 & 0.0 & 0 \\
\hline 2005 & $1,071.0$ & 4 & 920.1 & 6 & 0.0 & 0 \\
\hline Total & $4,771.0$ & 29 & $5,375.2$ & 37 & 506.8 & 3 \\
\hline
\end{tabular}

${ }^{a}$ Other perils include European hail, Monaco earthquake, Puerto Rico hurricane, Taiwan earthquake, third-party casualty liability and bonds for which the peril was not disclosed.

\section{About the Authors}

Stanley Mutenga is Assistant Professor at the University of Salford, U.K., and visiting lecturer in risk and insurance at Cass Business School. His major research interests are insurance company risk analysis and funding, and insurance company operations efficiency and strategy. He is currently a director and chair of the audit committee on the board of Adactus Housing Group, U.K. He holds a Ph.D. in insurance studies from Cass Business School.

Sotiris K. Staikouras is Associate Professor of finance at Cass Business School, City University, London. His major research interests are risk analysis and management of financial institutions, asset pricing and financial modelling. He has worked as a research advisor at London Clearing House and as financial analyst for other institutions. He holds a Ph.D. degree in finance from Cass Business School, and his research has been published in various international journals. 